International Journal of Engineering \& Technology, $7(4.5)(2018) 316-319$
International Journal of Engineering \& Technology
SPC
Website: www.sciencepubco.com/index.php/IJET
Research paper

\title{
Stress Analysis of Pelton Turbine Distributor Using UG-NX Software
}

\author{
Chaman Lal Pal ${ }^{1 *}$, Dr. T.S. Desmukh ${ }^{2}$, Dr. V.K.Gahlot ${ }^{3}$ \\ ${ }^{1}$ Assistant Professor, Mechanical Engineering Department, ITM University, Raipur \\ ${ }^{2}$ Professor, Civil Engineering departments, MANIT, Bhopal \\ ${ }^{3}$ Professor, Civil Engineering departments, MANIT, Bhopal \\ *Corresponding author E-mail:palchaman0310@gmail.com
}

\begin{abstract}
The main objective of this paper is analysis of stress in the distributor to find out optimum thickness for safe and satisfactory working at different load condition. To describe how different plate segments required fabricating wyes branches to ensure greater reliability. The distributor of Pelton turbine consists of pipe segments and wyes branches which are then connected to nozzle. A wyes branch, where the distributor bifurcates has a very complex shape and is very difficult to design. A practical case of distributor of 6 jets vertical Pelton turbine of $43 \mathrm{MW}$ power has been carried but using UG-NX software.
\end{abstract}

Keywords: Analysis; distributor; Pelton; UG-NX software; stress.

\section{Introduction}

Hydroelectric power is one of the major sources of energy throughout the world and is the cheapest and most pollution free source of electric power. In the world of hydropower, the total power available in water under pressure is converted into mechanical energy by the use of different types of hydro turbines under different working condition of head and discharge. The hydro turbines can broadly be classified into two classes, i.e. reaction and impulse turbine, depending on the energy exchange between the runner and the flow. Hydropower turbines are classified based on head height, or the height of the fall of water is as below-

Low head (10 to $60 \mathrm{~m}$ ) - Kaplan turbine

Medium head (30 to 500m) - Francis turbine

High head (more than 250m) - Pelton turbine

Pelton turbines belong to the family of free jet turbines. Pelton turbines with a horizontal shaft are designed with up to three nozzles; turbines with a vertical oriented shaft have three to six nozzles.

Distributor is the part of the Pelton turbine to facilitate pressurized water flow from MIV (Main Inlet Valve) and to feed to the nozzle-jet assembly, which in turn strikes the water jet to the runner buckets. In multi-jet turbine system, distributor is surrounding the runner. The turbine distributer is composed of curved pipes with bends and bifurcations. The purpose of distributor is to share evenly the flow between the nozzles (from 1 to 6 ) from which the jets are ejected towards the runner converting the potential energy of flow into kinetic energy.

The overall dimensions and shape of the distributor are determined on the basis of following considerations: -

a) The water should enter in each nozzle-jet assembly at a uniform flow rate. b) The flow in the distributor should satisfy the equal area of cross-section through each nozzle-pipe.

The distributor of Pelton turbine is shown in fig. 1

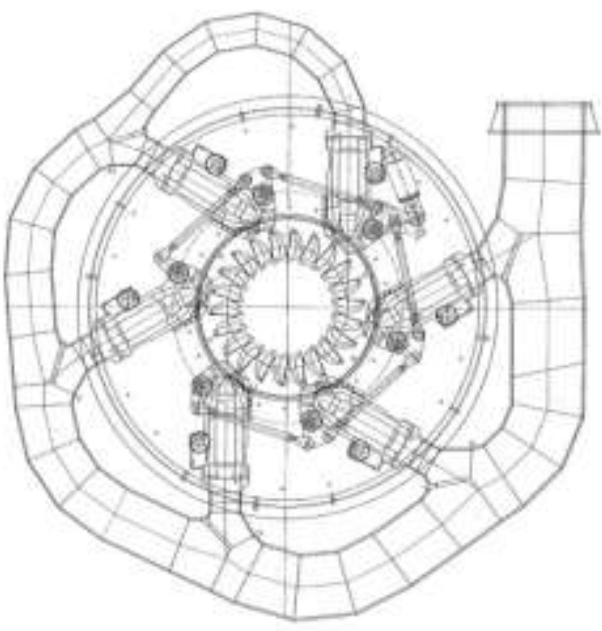

Fig. 1: Multi Nozzle distributor arrangement.

\section{Design of Distributor}

\subsection{Making a Solid Model}

We modify the distributor which design with cast wye branches. The present work distributor the application of a totally fabricated distributor, with wyes branches as well as connector pipes being manufactured by fabrication.

The preliminary thickness is assumed on the basis of previous projects which have the nearly same head \& output. The inlet \&outlet dia. of the distributor is $1100 \mathrm{~mm}$ and $523 \mathrm{~mm}$. if it is 
required to determine the thickness of distributor so that it can withstand a given internal pressure $p$ then we have to ensure that the maximum stress developed in the shell does not exceed the permissible tensile stress $(\sigma t)$ of the shell material. Since the circumferential stress is higher one, therefore, the shell is designed on this stress basis.

Now, $\sigma c=p d / 2 t$, where $t$ is the required thickness of the shell.

Table 1: Chemical composition of material
\begin{tabular}{|l|c|}
\hline Steel grade & P460NL1 \\
\hline Material number & 1.8915 \\
\hline$\%$ by mass(max) & \\
\hline $\mathrm{Fe}$ & 95.02 to 95.6 \\
\hline $\mathrm{C}$ & 0.2 \\
\hline $\mathrm{Si}$ & 0.6 \\
\hline $\mathrm{Mn}$ & 1.1 to 1.7 \\
\hline $\mathrm{P}$ & 0.025 \\
\hline $\mathrm{S}$ & 0.01 \\
\hline $\mathrm{Al}$ & 0.02 \\
\hline $\mathrm{Cr}$ & 0.3 \\
\hline $\mathrm{Cu}$ & 0.7 \\
\hline $\mathrm{Mo}$ & 0.1 \\
\hline $\mathrm{N}$ & 0.025 \\
\hline $\mathrm{Nb}$ & 0.05 \\
\hline $\mathrm{Ni}$ & 0.8 \\
\hline $\mathrm{Ti}$ & 0.03 \\
\hline $\mathrm{V}$ & 0.2 \\
\hline $\mathrm{Nb}+\mathrm{Ti}+\mathrm{V}$ & 0.22 \\
\hline
\end{tabular}

The initial thickness we used are 25, 27, 42, \& 48mm.

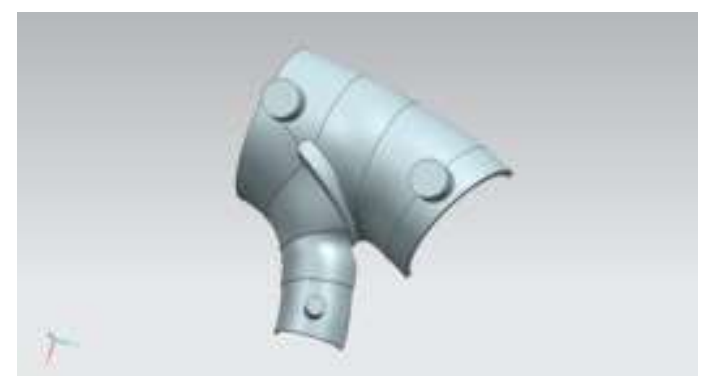

Fig. 2: wye branch of distributor

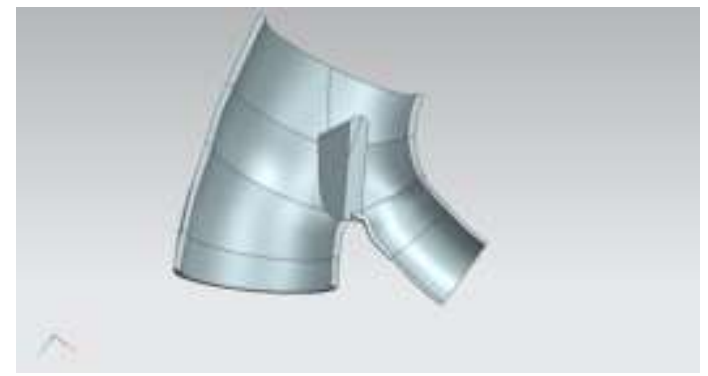

Fig. 3: wye branch of distributor (inner face)

\subsection{Mesh Generation}

For meshing of different segments of the distributor following mesh properties are used: -

Total number of meshes in the part: 1

Total number of elements in the part: 5061

Total number of nodes in the part: 10320

Element type: C Tetra (10)

Element size: 96.2

Max.Jacobian:10

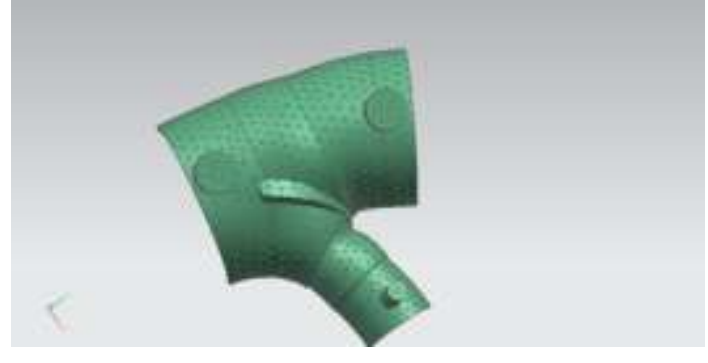

Fig. 4: Meshing of Wye-2

\subsection{Applying Boundary Condition}

Load, constraints, and simulations objects are all considered boundary conditions. User can also create boundary conditions using icon on the Advanced Simulation Toolbar.

Following boundary condition are applied in the distributor.

I. The symmetric boundary condition is applied for all the segments as the segment are spilited in two parts.

II. The fixed boundary condition is applied at the edges of the spilited segments.

III. The pressure of $60.6 \mathrm{~kg} / \mathrm{cm}^{2}$ is applied all over the model for various segments of distributor.

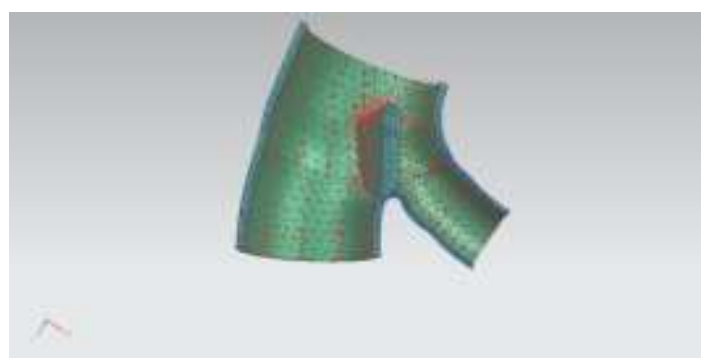

Fig. 5: Loading\& Boundary Condition on wye branch

\section{Result \& Discussion}

Stress analyses for all the segments of distributor are done successfully using NASTRAN SOLVER. For this purpose, the models are prepared using parametric modeling method. Advantage of parametric modeling is that any dimension, model updated automatically.

The result of various segments is shown in figures in which

Red Color- shows region of maximum stress.

Blue Color- shows region of minimum stress.

Intermediate Color- shows regions having stress values between maximum and minimum.

If the maximum stress as indicated by red color exceeds the maximum allowable stress, then plate thickness is changed. Again the program is run with new sets of inputs and analysis is performed. The process is repeated again \&again until the maximum stress in all the segments of the distributor is less than maximum allowable thickness of various segments of the distributor.

Table 2: Allowable Mechanical Properties of Material

\begin{tabular}{|c|c|c|}
\hline Steel Grade & Name & P460N1 \\
\hline & Material Number & 1.8915 \\
\hline Usual Delivery Condition & & $\begin{array}{c}\text { Normal- } \\
\text { ized }\end{array}$ \\
\hline Yield Strength $\left(\mathrm{N} / \mathrm{mm}^{2}\right)$ & $<16 \mathrm{~mm}$ & 460 \\
\hline & $>16$ to $<35$ & 450 \\
\hline & $>35$ to $<50$ & 440 \\
\hline & $>50$ to $<70$ & 420 \\
\hline & $>70$ to $<100$ & 400 \\
\hline
\end{tabular}




\begin{tabular}{|c|c|c|}
\hline $\begin{array}{c}\text { Tensile Strength (N/mm }{ }^{2} \text { ) For Prod- } \\
\text { uct Thickness in mm }\end{array}$ & $>100$ to $<150$ & 380 \\
\hline & $>70 \mathrm{~mm}$ & 570 To 720 \\
\hline & $>100$ To $<150$ & 520 To 690 \\
\hline $\begin{array}{c}\text { Elongation (\%) For Product Thick- } \\
\text { ness in mm }\end{array}$ & $<70 \mathrm{~mm}$ & 17 \\
\hline & $>70$ To $>150$ & 16 \\
\hline
\end{tabular}

In case of wye-2, for first iteration the model has been prepared without using the sickle plate, the FEM \& stress analysis is carried out, the maximum stresses are above the limit at wye section. The thicknesses of various sections taken are $25,27,42, \& 48 \mathrm{~mm}$.

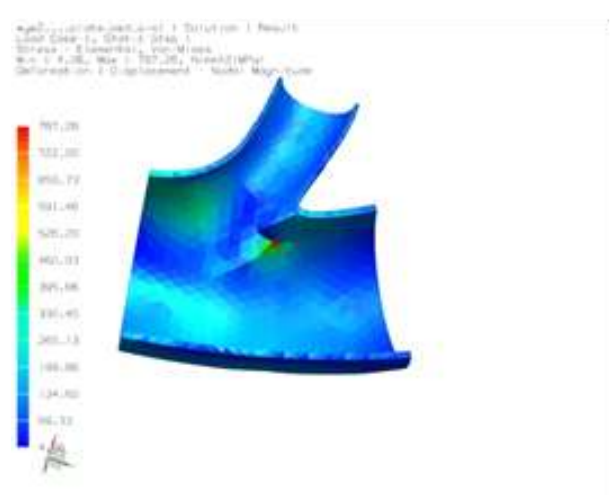

Fig 6: First Iteration of Wye -2

For second iteration of one of the section (near wye section) is increased from 42 to $44 \& 48$ to $50 \mathrm{~mm}$. sickle of $100 \mathrm{~mm}$ thickness is placed at wye section (to reduce the average stress). Now the FEM \&stress analysis is carried out, the maximum stresses are $787.7 \mathrm{~N} / \mathrm{mm}^{2}$ at sickle plate \&average stresses are $397.85 \mathrm{~N} / \mathrm{mm}^{2}$.

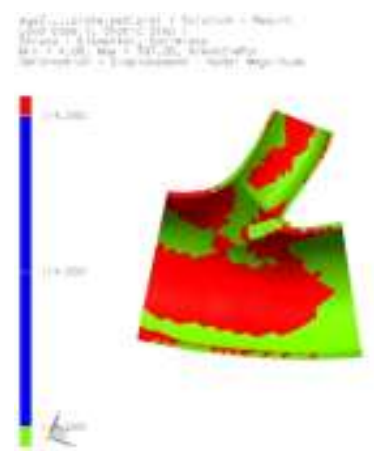

Fig 7: Second Iteration of Wye -2

For third iteration, thickness of sickle plate increased from100 to $130 \mathrm{~mm}$ and thickness at wye section 44 to $46 \mathrm{~mm} \& 27$ to $32 \mathrm{~mm}$. Now the FEM \& stress analysis is carried out, the maximum stresses are $98.45 \mathrm{~N} / \mathrm{mm}^{2}$ at sickle plate \&average stresses are $50 \mathrm{~N} / \mathrm{mm}^{2}$.

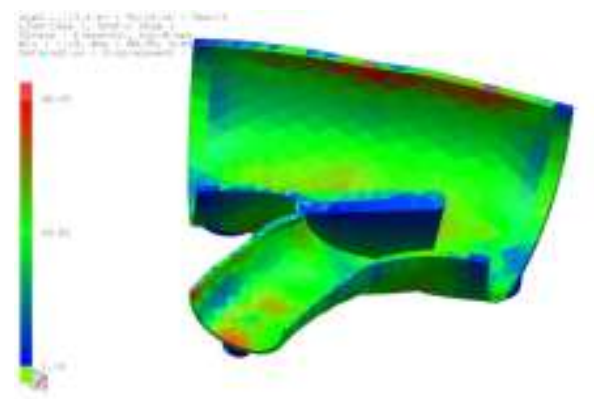

Fig 8: Third Iteration of Wye -2

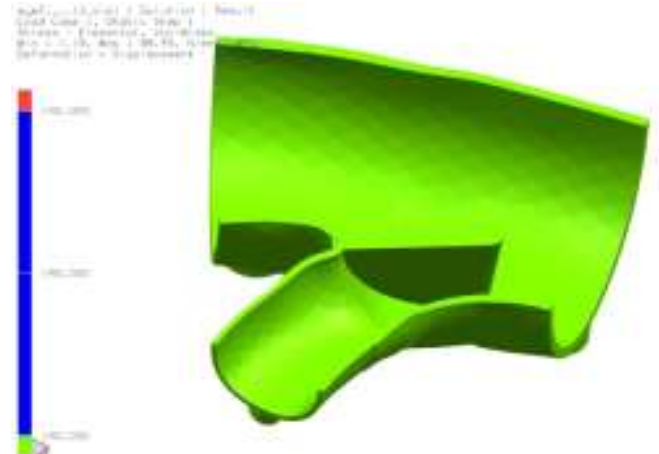

Fig 9: Final Result of Wye -2

As per design norms, if the average stress is less than $1 / 5^{\text {th }}$ of ultimate tensile strength of material or $1 / 3^{\text {rd }}$ of the yield strength of the material it is taken as acceptable design. Here as the value of average stress $\left(50 \mathrm{~N} / \mathrm{mm}^{2}\right)$ is below the $1 / 5^{\text {th }}$ of ultimate tensile strength of material $\left(570 / 5=114 \mathrm{~N} / \mathrm{mm}^{2}\right)$ or $1 / 3 \mathrm{rd}$ of the yield strength of material $\left(450 / 3=150 \mathrm{~N} / \mathrm{mm}^{2}\right)$, So this value has been accepted.

\section{Conclusion}

In the present work distributor has been analysed to check effectiveness of various design features and the optimization of structure under various conditions. From the analysis, the general observations and conclusion:

- $\quad$ Fabrication is more convenient method of manufacturing a distributor. It reduces the manufacturing time considerably as compared to the casting variant. In fabrication technique, the entire distributor is broken into large number of small piece. Steel plate of required size for various pieces are taken, rolled and joined by welding to form a distributor.

- As per the general practice of design of a distributor, the allowable safe pressure within a distributor must be lies than $1 / 3^{\text {rd }}$ of the tensile strength or $1 / 5^{\text {th }}$ of ultimate tensile strength of chosen material.

- $\quad$ FEM has a very effective tool for designers in the field of structural of design of hydraulic components.

- As the stresses increased the permissible limits in some segments, been made to arrive at a safer value of pressure. The final thickness of plates obtained are $25,32,46,50 \mathrm{~mm}$.

- From the present work, a distributor for a Pelton turbine has been designed. Better safety margins have been achieved. The analysis gives saving in total cost of design.

\section{Acknowledgement}

I express my deep sense of gratitude to Mr. Omeshwar Daheekar, Senior Design Engineer, BHEL Bhopal for closely supervising this work and offering many innovative idea and helpful suggestion.

\section{References}

[1] Argyris J.H. (1954)." Recent Advances in Matrix Methods of Structural Analysis", Pergamon Press, Elmsford, NY.

[2] Ausoni Ph., Farhat M., Bouziat Y.A., Kueny J.L., Avellan F. (2006)," Karman vortex shedding in the wake of a hydrofoil; Measurement and numerical simulation" IAHR Int. Meeting of WG on cavitations and Dynamic Problems in Hydraulic Machinery and system, Barcelona, Spain, June28-30.

[3] Avadesh K. Sharma (2012)," Design Analysis of Pressure Vessels at high stress zones using Pro/E v4.0".

[4] Clough R.W. (1960)," The Finite Element Method in Plane Stresses Analysis, "Proceeding of 2nd ASCE Conference on Electronic computation, Pittsburgh, P A, September 8-9. 
[5] Zienkiewicz O.C. and Cheung Y.K. (1965)," Finite Elements in the solution of field problems," Engineer, Vol.220, pp.507-510.

[6] Zoppe B., Pallone C., Maitre T.," Flow analysis Inside a pelton turbine bucket" France vol.128 July 2006.

[7] Barlit V. V., Krishnamachar P., Gahlot V. K.," Hydraulic Turbine (hydraulic theory \& design approach) volume-II.

[8] Bhandari V B,' Design of Machine Elements', Tata McGraw-Hill Publication.

[9] Jagdish Lal, Textbook of "Hydraulic Machine “, Metropolitan book Pvt. Ltd. Delhi.

[10] Zienkiewicz, O.C. and Taylor, R.L. (1989). The Finite Element Method, 4th ed., McGraw Hill Book Company, Maidenhead, UK

[11] HAP - Best Practice Catalogue - Pelton Turbine, Prepared by MESA ASSOCIATES, INC., Chattanooga, TN 37402. 